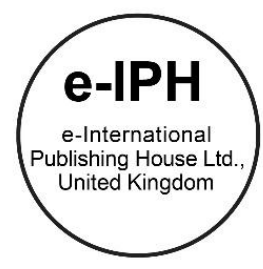

\title{
Behavioral Program and Exercise Training for Older Persons: Effect on cardio respiratory fitness
}

\author{
Azliyana Azizan1, Maria Justine², Noor Amiera Alias² \\ ${ }^{1}$ Department of Physiotherapy, ${ }^{2}$ Department of Occupational Therapy, \\ Faculty of Health Sciences, \\ Universiti Teknologi MARA, Kampus Puncak Alam, 42300, Shah Alam, Malaysia \\ azliyana9338@puncakalam.uitm.edu.my \\ Tel:+6014-6992873
}

\begin{abstract}
Active participation in exercise may help to improve physical and psychological functions for older people. Regretfully, most of them do not engage in long term exercise due to several barriers. This puts them at high risk of may chronic illness that will limit their activities of daily living. The aim of this study is to determine the effectiveness of the behavioral and exercise program on cardio respiratory fitness among 63 community-dwelling olders. At the end of six months, there is a significant difference for cardio respiratory fitness and exercise engagement. Thus, improved their overall quality of life.
\end{abstract}

Keywords: Behavioral; Cardiorespiratory; Exercise; Older

eISSN: 2398-4287@ 2017. The Authors. Published for AMER ABRA by e-International Publishing House, Ltd., UK. This is an open access article under the CC BYNCND license (http://creativecommons.org/licenses/by-nc-nd/4.0/). Peer-review under responsibility of AMER (Association of Malaysian Environment-Behaviour Researchers), ABRA (Association of Behavioural Researchers on Asians) and cE-Bs (Centre for Environment-Behaviour Studies), Faculty of Architecture, Planning \& Surveying, Universiti Teknologi MARA, Malaysia.

https://doi.org/10.21834/e-bpj.v2i6.938

\subsection{Introduction}

The world population of an older person aged 65 and older has increased. Among the 7.3 billion people worldwide in 2015, the number of the elderly ( 65 years and older) in the world is estimated $8.5 \%$ or 617.1 million. This number is projected to increase more than $60 \%$ in just 15 years more (Kowal, Goodkind \& He, 2016). While the ageing transition has occurred in young developed countries, same goes to Malaysia as well. Distribution of population in Malaysia, aged 65 years and above increased from $5.8 \%$ in 2015 to 6\% in 2016 (Department of Statistics Malaysia, 2015a). The life expectancy at birth for the male is 71.7 years and for the female is 76.4years and total life expectancy is 73.9 years (Department of Statistics Malaysia, 2015a). This increase in longevity among older persons results in many problems, including age-associated disease and functional limitations. Body composition changes characterise with ageing, a decline of motor units, conversion of the fast twitch type II muscle fibres into slow twitch type I fibres (Pasco \& Brennan Olsen, 2016), nutritional status and increased risk of chronic diseases. Physical activity tends to decrease with age. Studies reported that a decline in voluntary physical activity which is associated with reductions in several measures of cardiorespiratory fitness, including maximal aerobic capacity, muscle strength, and fatiguability leading to an increased risk of frailty (Mcphee et al., 2016). Also, reports from National Health and Morbidity Survey revealed that over the previous 30 years, there were progressive decreases in the level of physical activity among Malaysian population. Most studies claimed that older persons who had low to moderate level of physical activity might be very risky for them to develop a cardiovascular problem. Results from Malaysian National Cardiovascular Disease (NCVD) Database Registry (March 2006 until February 2010) have shown that the mean age of

eISSN: 2398-4287@ 2017. The Authors. Published for AMER ABRA by e-International Publishing House, Ltd., UK. This is an open access article under the CC BYNCND license (http://creativecommons.org/licenses/by-nc-nd/4.0/). Peer-review under responsibility of AMER (Association of Malaysian Environment-Behaviour Researchers), ABRA (Association of Behavioural Researchers on Asians) and cE-Bs (Centre for Environment-Behaviour Studies), Faculty of Architecture, Planning \& Surveying, Universiti Teknologi MARA, Malaysia.

https://doi.org/10.21834/e-bpj.v2i6.938 
acute coronary syndrome patients at presentation was 59.1 years. Aye, Cabot and Sazali, (2015) did report that most of the cardiovascular disease mortality in a rural area in Malaysia was due to rapid urbanization, industrialization, and sedentary lifestyle changes. Therefore, it is important for other health professionals to find the best ways in managing this type of diseases. As the exercise and physical activity has been shown to have beneficial effects on cardiorespiratory fitness, particularly in cardiac effects and vascular effects. However, most of the older persons particularly do not engage in any exercise or physical activity for long-term due to several barriers (Justine, Azizan, Hassan, Salleh, \& Manaf, 2013). Most of these relate to the behavioural factors. Thus it is an urgency to look and implement a program to help older persons for actively engage in physical activity and improve their overall quality of life.

Cardiorespitarory fitness directly correlates with the ability to transport and metabolise oxygen during physical exertion. A peak aerobic power (VO2max) of 15-20 ml/kg per min is necessary to support independent community living; sedentary individuals often reach this milestone by age 80-85 years (Shephard, 2007). A natural decline in peak oxygen transport occurs that accelerates after age 50 years when losses can average $0.4-0.5 \mathrm{ml} / \mathrm{kg}$ per minute per year, equivalent to $5 \%-10 \%$ per decade (ACSM, 2009). These declines in the cardiorespiratory fitness among older persons has been attributed to progressive and cardiac muscle deconditioning. However, the techniques that measure this VO2 max require the participant to wear an expiratory gas mask which is not comfortable and running on the treadmill which induces lower limb fatigue and might induce discomfort. Also, this way of testing for exercise tolerance was not practical, a bit costly and time-consuming for an older person, especially for frail. Therefore, objectives in this study is to determine the effects of exercise and behavioural program into the the level of cardiorespiratory fitness among communitydwelling elderly.

\subsection{Methods}

\subsection{Participants}

A total of 63 participants has conveniently participated in this study. Three different groups were formed based on various locations; (1) EBG (Exercise and behavioural program) $(n=18), 2)$ EG (Exercise only) ( $n=23)$, and 3) CG (Control) $(n=22)$. Each group received different interventions such; EBG performed the exercise for six weeks followed by another five weeks of the behavioural program. EG performed only the exercise for six weeks, while CG did not perform any intervention but was given an introductory session for the importance of physical activity and exercise. Participants were included if they met the following criteria: (1) age 60 years old and above, (2) no cognitive impairments (MMSE results less than 24 scores were excluded) (Smith, Gildeh, \& Holmes, 2007), (3) independent in activities of daily living, (4) able to understand and communicate in English/Malay and (5) stay in own village/study setting. Participants who had severe orthopaedic conditions (e.g., joint deformities, osteoarthritis), and had neurologic disorders (e.g., Parkinson's disease and traumatic brain injury) were excluded. The institutional ethic committee was approved the study protocol, and each participant signed written informed consent, as before they participate in the program.

Outcome measure

The present study used a control quasi-experimental study designed. We measured participants' cognitive function with MMSE and six-minute walk test. The 6-MWT measures the distance an older person can walk over a total of six minutes on a hard, flat surface. The goal is for the each participant is to walk as far as possible in six minutes. In this test, each participant was allowed to self-pace and rest if he or she needed. They also allowed walking traverses back and forth along a marked walkway within the time given. It demonstrates that the 6-MWT is a valid and reliable measure of cardiorespiratory fitness in healthy older person in the community as we as those had the chronic respiratory disease or heart failure. Scoring was done based on the distance achieved by the participants within the given time. A lower score (reflecting the less distance covered in 6 minutes) indicates worse function and cardiorespiratory. The six-minute walk distance in healthy adults has been reported to range from $400 \mathrm{~m}$ to $700 \mathrm{~m}$ (Enright,2003). The test for cardiorespiratory fitness was measured using 6-MWT at 5-times points, at baseline, six, twelve, eighteen and twenty-four weeks.

\subsection{Interventions}

\section{Exercise Program}

The group-based exercise program has followed the guidelines from Justine and Hamid (2010), with adjustment for the type of movements, intensity, and volume of activities. It is consists of 18 sessions (three times a week and one hour per session) for six weeks. It is a multicomponent exercise program, and the cardiorespiratory session was a major component. We conducted this program for at least 150 minutes of moderate-intensity exercise per week as recommended by the ACSM guidelines. We also performed a gradual progression of exercise time, frequency, and intensity for this program to create exercise adherence and less injury risk among the participants.

\section{Behavioral Program}

The participants from the EBG received this behavioural program following the completion of the exercise program. This program was structured and goal oriented, as focused on increasing exercise adherence as well as long-term motivates for long-term involvement in exercise participations. This program been earlier reported in Azizan et al. (2013) and was conducted three times a week for five weeks. Several strategies were being practised such as (1) Use of a motivators worksheet, (2) Use on a 'behavioural contract', (3) face to face interview, (4) counselling, (5) group discussion, and (6) role modelling sessions. All these strategies include ways to change the attitude and sedentary behaviour among older persons. 


\subsection{Statistical analysis}

Statistical analysis has done by using the PASW Statistics 20 software. Descriptive statistics were performed to obtain the means and standard deviations of the variables of interest. A one-way ANOVA and $3 \times 2$ Chi-square tests were used to determine the baseline demographic differences between groups. The analysis of covariance was conducted to determine the presence of confounding variables at baselines for all groups. To determine whether there were time factor effects, group effects, and interaction between the two factors (group and time) for all groups, the repeated measures analysis of variance (ANOVA) was used. A change in the endurance performance was the main outcomes of this study. Results were reported as means ( $m$ ) and standard deviations (SD). The level of statistical significance was set at 0.05 .

\subsection{Results}

The mean age of participants was $63.8(S D=4.5$ years). The mean height, body weight and BMI were $1.55(S D=0.12 \mathrm{~m}), 63.53 \mathrm{~kg}$ $(S D=10.87 \mathrm{~kg})$, and $26.42 \mathrm{~kg} / \mathrm{m}^{2}\left(S D=4.52 \mathrm{~kg} / \mathrm{m}^{2}\right)$ respectively. The baseline characteristics of study participants are shown in (Table 1). There were no significant differences between the groups on demographic characteristics except for age variable and no significant differences between groups on endurance performance at baseline.

Table 1. Characteristics of study participants $(n=63)$ at baseline

\begin{tabular}{|c|c|c|c|c|c|c|c|c|}
\hline \multirow[t]{2}{*}{ Character-istics } & \multicolumn{2}{|c|}{ EBG Group (n=18) } & \multicolumn{2}{|c|}{ EG Group (n=23) } & \multicolumn{2}{|c|}{ CG Group (n=22) } & \multirow{2}{*}{$\begin{array}{l}\text { Test statistics } \\
\text { (F-test) }\end{array}$} & \multirow[t]{2}{*}{ Sig } \\
\hline & $\mathrm{n}(\%)$ & $\mathrm{m} \pm \mathrm{SD}$ & $\mathrm{n}(\%)$ & $\mathrm{m} \pm \mathrm{SD}$ & $\mathrm{n}(\%)$ & $\mathrm{m} \pm \mathrm{SD}$ & & \\
\hline Age(years) & & $66.1(6.21)$ & & $63.5(3.39)$ & & $62.3(3.07)$ & & $0.025^{*}$ \\
\hline $\begin{array}{l}\text { Gender } \\
\text { Female } \\
\text { Male }\end{array}$ & $\begin{array}{l}8(44.4) \\
10(55.6)\end{array}$ & & $\begin{array}{l}15(65.2) \\
8(38.4)\end{array}$ & & $\begin{array}{l}12(54.5) \\
10(45.5)\end{array}$ & & 0.872 & 0.411 \\
\hline Body weight (kg) & & $\begin{array}{l}59.82 \\
(3.33)\end{array}$ & & $\begin{array}{l}65.89 \\
(2.16)\end{array}$ & & $\begin{array}{l}64.187 \\
(1.66)\end{array}$ & 1.642 & 0.202 \\
\hline Height (m) & & $1.53(0.03)$ & & $1.56(0.02)$ & & $\begin{array}{l}1.57 \\
(0.02)\end{array}$ & 0.659 & 0.521 \\
\hline BMI $\left(\mathrm{kg} / \mathrm{m}^{2}\right)$ & & $\begin{array}{l}25.83 \\
(1.58)\end{array}$ & & $27.05(0.65)$ & & $\begin{array}{l}26.27 \\
(0.761)\end{array}$ & 0.370 & 0.692 \\
\hline $\begin{array}{l}\text { Exercise } \\
\text { Tolerance } \\
\text { (6 MWT) }\end{array}$ & & $\begin{array}{l}296.20 \\
(46.132)\end{array}$ & & $312.19(48.170)$ & & $\begin{array}{l}310.46 \\
(52.700)\end{array}$ & 0.615 & 0.544 \\
\hline
\end{tabular}

The ANCOVA for age as the covariate was conducted for exercise tolerance at baseline due to its significant difference $(p<0.05)$. The results revealed that age was not a confounding factor for the exercise tolerance $[F(2,59)=0.37, p=0.69]$.

There was a statistically significant main effect for time factor $\left[F(2.10,125.83)=22.14, p<0.05, \eta^{2}=0.27\right]$. We have also found a significant main effect of the group factor $\left[F(2,60)=17.29, p<0.05, \eta^{2}=0.37\right]$. When we examined the table for possible interaction effect between the time and group, there is significant as $\left[F(4.19,115.83)=36.07, p<0.05, \eta^{2}=0.55\right]$. The post hoc comparison using the Bonferroni test for mean difference between three groups in term of exercise tolerance has shown significant mean differences for [ $E B G$ and $E G=47.18$; $E B G$ and $C G=86.59$; $E G$ and $C G=39.41$ ] with $p$-value $<0.05$. Below are the mean differences and standard deviations across five time points for each group. (Table 2).

Table 2. Mean and percentage of change in the exercise tolerance

\begin{tabular}{|c|c|c|c|c|c|c|c|c|}
\hline \multirow{2}{*}{$\begin{array}{l}\text { Time } \\
\text { period }\end{array}$} & \multicolumn{2}{|l|}{ EBG } & \multicolumn{2}{|l|}{ EG } & \multicolumn{2}{|l|}{ CG } & \multirow[t]{2}{*}{ P-value } & \multirow{2}{*}{$\begin{array}{l}\text { Mean Difference between group } \\
\text { (T-test) }\end{array}$} \\
\hline & $\mathrm{n}$ & Mean (SD) & $\mathrm{n}$ & $\operatorname{Mean}(\mathrm{SD})$ & $\mathbf{n}$ & Mean(SD) & & \\
\hline & & & \multicolumn{5}{|c|}{ The Exercise Tolerance (6MWT) } & \\
\hline Baseline & 18 & $296.20(46.13)$ & 23 & $\begin{array}{l}312.19 \\
(48.17)\end{array}$ & 22 & $310.46(52.70)$ & 0.54 & $\begin{array}{l}E B G-E G=15.99 \\
E B G-C G=14.26 \\
E G-C G=1.72\end{array}$ \\
\hline $6^{\text {th }}$ week & 18 & $363.69(47.79)$ & 23 & $\begin{array}{l}386.04 \\
(46.25)\end{array}$ & 22 & $301.86(53.16)$ & $0.00^{*}$ & $\begin{array}{l}\text { EBG-EG }=22.35 \\
\text { EBG-CG }=61.83^{*} \\
E G-C G=84.18^{*}\end{array}$ \\
\hline $12^{\text {th }}$ week & 18 & $388.94(45.30)$ & 23 & 336.65 & 22 & $282.91(69.33)$ & $0.00^{*}$ & EBG-EG $=52.29^{*}$ \\
\hline
\end{tabular}




\begin{tabular}{|c|c|c|c|c|c|c|c|c|}
\hline $18^{\text {th }}$ week & 18 & $398.28(45.54)$ & 23 & $\begin{array}{l}299.74 \\
(44.84)\end{array}$ & 22 & $270.64(73.64)$ & $0.00^{*}$ & $\begin{array}{l}\text { EBG-EG }=98.54^{*} \\
\text { EBG-CG }=127.64^{*} \\
\text { EG-CG }=29.10\end{array}$ \\
\hline $24^{\text {th }}$ week & 18 & $405.94(42.18)$ & 23 & $\begin{array}{l}282.52 \\
(43.14)\end{array}$ & 22 & $254.23(73.33)$ & $0.00^{*}$ & $\begin{array}{l}\text { EBG-EG }=123.42 ; \\
\text { EBG-CG }=151.72^{*} \\
\text { EG-CG }=28.29\end{array}$ \\
\hline
\end{tabular}

Note: ${ }^{*}$ significant at $p<0.05$.

\subsection{Discussion}

The finding of this current study showed a positive effect of exercise and behavioural program on the level of cardiorespiratory fitness among community-dwelling older persons. The increased level of cardiorespiratory fitness in the EBG was higher compared to EG and CG group. It is observed to have a significant increase in mean walking distance from $296.20 \mathrm{~m}$ at baseline to $363.69 \mathrm{~m}, 388.94 \mathrm{~m}$, $398.28 \mathrm{~m}$ and $405.94 \mathrm{~m}$, for every six weeks, respectively. The progressive increase in the total walking distance is because the participant in EBG had benefited from the continuous exercising training and behavioural influences. The researcher believes that these increasing numbers of difference were significant, even with small changes in determining participants' response to intervention. Further, the combined program for older persons that received in EBG more focuses on active engagement, individualised, selfdirected and valued activities (Dahlan, Anwar, \& Ibrahim, 2017), which should be a part of the rehabilitation programme for an older person. Furthermore, the author seriously adds safety issues in conducting the program. Ismail, Ahmad, Afida, Janipha, and Ismail, (2017) claimed that a safety component is a major factor in enhancing positive behaviours, such as empower leadership skills, increase commitment and more resources regarding active engagement in physical activity.

Also, previous studies were shown that multifactorial interventions had improved walking performance in term of distance or gait speed in older people (Ellis et al., 2013; Fairhall et al., 2012). Similarly, their families and friends would have motivated The EBG participants, who contributed to increase in walking distance and this signifies that apart from a routine exercise programme, other modes of interventions are necessary to promote. The results from the role model sessions in the behavioural program put them in a positive reinforcement to perform a better walking performance (Majid, Danis, Sharoni, \& Khalid, 2015). In these sessions, each participant had experienced a positive model by someone who shows the way, someone who supports in exercising or show the way to persist in spite of difficulties and how to get around obstacles in exercising at a later age. Fujimoto et al., (2010) have shown that endurance training improves measurements of cardiovascular performance in healthy older persons as expressed by an increase in peak $\mathrm{VO}_{2}$. Therefore, those participants who continued performing an exercising, especially endurance training that might have promoted adaptation of the cardiovascular system. Similarly seen in EBG group, they can sustain in enduring walking for six minutes. Also, the EBG gained valuable benefits as they participated behavioural strategies such as goal setting, counselling, group discussions and receiving a behavioural manual. The EBG gained their confidence and a sense of belongings when they self-made an exercise group every day after the formal training (Abdul Mutalib, Haji Dahlan, \& Danis, 2017). In addition, the majority of the participants in EBG were self-reported that they make their open space such as a garden nearby community hall and aeroponic plant. They enjoyed making an open space and interact each other (Hussein, Nik Zainal Abidin, \& Omar, 2016; Hussein, Omar, \& Ishak, 2016). Previous studies also supported that Gan open space increase the level of unity with nature, the unity with themselves, and sense of freedom, recreational satisfaction, adventure, and happiness (Omar, Illia, Hanita, \& Mohamad, 2017; Yousefi, Hosseini, Yazdanfar, \& Norouzian-maleki, 2017).

It is well-known that sedentary older persons who indulge in short-term engagement in an exercise program, resulted in declining in cardiorespiratory fitness (Magistro, Liubicich, Candela, \& Ciairano, 2013) as shown by EBG and EG. The results from this current study revealed that both EBG and EG gained benefits after they participated in the exercise program, conducted for six weeks. The participants in EBG had high level of exercise adherence and positive behavior that can continuously promoted exercise tolerance through the following weeks, on the other hand (Mamat, Mahamood, \& Ismail, 2012); the EG started to decline after the termination of the exercise program. In this perspective, the researcher had new key findings which improved exercise capacity or exercise tolerance resulted from a predesigned exercise protocol. In this present study, the exercise training was developed based on the recommendation of American College of Sports Science (ACSM) by combining four types of training and inclusion of music. The thought behind playing the music was to motivate and create an environment to perform exercises enjoyable thereby increasing the intensity of the exercises (Abdul \& Shukri, 2016). The intensity used for this program was low to moderate intensity for the first two weeks (in a sitting position), to familiarise the participants with the nature of the exercise pattern. While, the next four weeks, the exercises were conducted at a moderate intensity (in a standing position). The researcher agreed that it was important to keep the intensity at a reasonable level to promote adherences prevent dropouts among the participant in exercise training.

Respiratory muscles are the skeletal muscles that are functionally similar to locomotor muscles. Their primary task is to act upon the chest wall to move gas in and out of the lungs to keep arterial blood gas and $\mathrm{pH}$. Regular endurance training will increase respiratory muscle oxidative capacity and improves respiratory muscle endurance (Shepherd et al., 2014). The endurance training was reported to increase the oxidative capacity of upper airway muscles, which is important because these respiratory muscles play a 
crucial role in maintaining open airways to reduce the work of breathing during exercise. For this reason, those participants who undergo endurance training regularly, they had more energy and less fatigue during the exercise. In EBG, the participants will continue exercising after the formal exercise training and increase their physical activity. Even small compound near their house, they had a garden to fulfil their need. They also had a gated area, to improve their level of satisfaction in the community (Nirfalini \& Majid, 2016). It is because a positive value was of the park nearby their house (Shukur, Othman, \& Nawawi, 2012). The participants in EBG implemented an Islamic way for their garden, as Md Jani, Harun, Mansor, and Zen, (2017) also reported that this kind of garden would remind them of the oneness of God, that He is the creator of the universe. It is thought that they were able to adapt more energy every week as they increased their level of endurance. In contrast to EG and CG, which showed the progressive declined in their muscle endurance showed in the number of walks distanced. They might think that a six-minute durations for a walking were tiring, exhausting and very hard to perform as they had poor respiratory muscle endurance.

The ability to continue prolonged, submaximal work is dependent on the maintenance of homeostasis during the activity. The participant in EBG and EG, who continued endurance training, had increased their performance in the 6-minute walk test due to biochemical and structural changes in the trained skeletal muscle than to a little increase in VO2 max. The reasons are that the endurance training caused substantial changes in the biochemical and structural characteristics of the working muscles. The typical changes included an increase in the number of mitochondrial and capillary density. Therefore, those who are continuing to perform the exercise, either by a group or alone will gain significant lower limb strength and better exercise endurance.

As participants in EBG increased higher in their exercise capacity, they proved that the behavioural program was effective. In the behavioural program, the participants can facilitate their environment through providing a safe environment to exercise, learning independence training skills which initiate the EBG to gain more control over their surroundings that gave the participants more control over their environment. In contrast, the participants who did not receive behavioural program showed low exercise tolerance. It was demonstrated by the declining total mean of walked distance from $386.04 \mathrm{~m}$ to $336.65 \mathrm{~m}, 299.74 \mathrm{~m}$ and $282.52 \mathrm{~m}$ for the EG and the CG also showed progressively declining overall mean walked distance from baseline, $310.46 \mathrm{~m}$ to $301.86 \mathrm{~m}, 282.91 \mathrm{~m}, 270.64 \mathrm{~m}$ and $254.23 \mathrm{~m}$, respectively. Previous studies also supported that a safer housing environment will create a stronger connection in the community and increase participation in daily activities (Karim \& Rashid, 2010; Laurens, 2012; Mansor, Said, \& Mohamad, 2012)

As the purpose of this study was to enhance the cardiorespiratory fitness objectively through exercise and behavioural program, the primary concern was to change the sedentary behaviour among older persons. The addition of five weeks of the behavioural program in this study was deemed successful to enhance a long-term participation in exercise. It would have increased the exercise tolerance among older persons. The participants in EBG had received a motivational interviewing, which similarly found in a report by Scales and Miller, (2003) which revealed that this motivational might have changed their behaviour to be the more positive attitude towards exercise. Irvine, Gelatt, Seeley, Macfarlane, and Gau, (2013) also claimed that web-based intervention has the advantages in giving a positive impact on the physical activity of sedentary older persons $(M=60.3 ; S D=4.9)$. Even though the web interventions which was different to the direct responses (as this study used motivational interviewing per se), but the concept was to educate, motivate and enhance the compliance of older persons to engage in exercises. Thus, this concept still can be practical and provide positive ways of improving the ongoing process of exercise participations, rather than a single intervention. Moreover, the direct responses are possible at the community setup, and the present study concept of training the older individuals are possible even in the rural setup as they are unable to access the internet.

The consistency and progressive improvement in the exercise tolerance occurred because the participant in EBG had a higher self-esteem and adhered to the exercise for a longer period. After six weeks of formal group-exercise, they also continued exercising at home or anywhere else. This study produces results, which corroborate the findings of the vast deal of the previous work in this field, that long-term exercise tolerance may reduce insulin sensitivity, mitochondrial dysfunction, and other age-related dysfunctions among healthy older persons (Lanza \& Nair, 2009). Justine et al., (2012) also reported that exercise could improve the cardiorespiratory performance up to $41.79 \%$ among institutionalised older persons who performed exercise training for 12 weeks and this seen in the present study by promoting functional exercise tolerance.

The short-term effects gained by the participants in the EG after the formal exercise program. As Toraman and Ayceman (2005) revealed that functional fitness of endurance, strength, balance, and flexibility was significantly lower after six weeks of detraining. The participants in EG did not continue exercising or had no initiative to create their groups to exercise as a result of less knowledge in practice. Similarly, the CG showed progressively decline in exercise tolerance since no exercise, or behavioural program was introduced to this group. Thus, the effects of ageing in older persons gradually took place. Structural and physiological effects of ageing might contribute to decrease in the exercise capacity (McCance, Huether, Brashers, \& Rote, 2010) among the participants in CG. Thus, an intervention was needed for this population to keep fit and maximise their level of exercise tolerance. Knowledge of exercise at a later age has become so much important as it may help older persons to understand why they should continue exercising and actively move around.

In count, a positive neighbourhood environment also contributes to a long-term exercise participation and thus improve exercise tolerance among older persons. A map highlighting walking routes on and off-site, pedometers and several behavioural strategies might be beneficial to support the walking activities (Abd-latif, Nor, \& Omar-fauzee, 2011; Abdul \& Shukri, 2016; Abdullah, Ahmad Saman, Kahn, \& Al-Kubaisy, 2016; Adawiyah, Sh, \& Zain, 2016). In this present study, a large benefit was gained as participants in EBG continued actively participating in the exercise training, either home or community hall. They were also aware that activities such as walking might give significant advantages for them.

This current study describes positive outcomes on the effects of combined exercise and behavioural program on exercise tolerance among older persons living in the community. It was a multi-approach strategy to educate, practice and change the 
behaviour among older persons to motivate them to adhere to the exercise program as long as possible. However, several limitations are highlighted as it was involved only one area, sub-urban. Different settings such as rural and urban might had differences results. Also, it involved Malay races in the interventions. Other races such as Indian, Chinese and other races might has different motivations and barriers towards exercising. Therefore, future studies should involve this to generalized population.

\subsection{Conclusion}

Regular exercises are promising interventions for the older person, and several studies are currently underway to examine their impacts. However, several interrelated areas need further investigation to promote long-term engagement in the exercise participation. First, adherence to an exercise regimen is a key to its valuable effects and strategies to overcome the barriers. Second, psychological and behavioural factors should be considered. Older persons who are not involved in the much physical activity may impact their ability to adhere a regular exercise regimen correctly (Samsuddin, Takim, \& Nawawi, 2017). Therefore, behavioural programs seem to be more practical and highly recommended in combining with an exercise program, as a means to promote the better quality of life.

\section{Acknowledgment}

This project was made possible by grants from the Research Management Institute (600-RMI/DANA 5/3/LESTARI [0095/2016]), Universiti Teknologi MARA, Selangor, Malaysia, via the Research Intensive Faculty/Excellence Fund.

\section{References}

American College of Sports Medicine. (1998a). Exercise and physical activity for older adults. Medicine and Science in Sports and Exercise, 30,6: 992-1008.

Abd-latif, R., Nor, M. M., \& Omar-fauzee, M. S. (2011). Influence of Recreational Facilities among Adolescents towards Leisure Time Physical Activity (LTPA). Asian Journal of Environment-Behaviour Studies, 38, 37-46. https://doi.org/10.1016/j.sbspro.2012.03.345

Abdul, S., \& Shukri, M. (2016). Creating Pro-Environmental Residents : The role of environmental knowledge. Asian Journal of Behavioural Studies, 1(2), 13-22.

Abdul Mutalib, A. S., Haji Dahlan, A., \& Danis, A. (2017). Financial Interdependence among Malay Older People in the Community: An interpretative phenomenological analysis. Environment-Behaviour Proceedings Journal, 2(5), 135. https://doi.org/10.21834/e-bpj.v2i5.689

Abdullah, N. N., Ahmad Saman, M. S., Kahn, S. M., \& Al-Kubaisy, W. (2016). Patterns of Quality Of Life among Older Urban Dwellers with Mobility Disability in Malaysia. Environment-Behaviour Proceedings Journal, 1(2), 55. https://doi.org/10.21834/e-bpj.v1i2.255

Adawiyah, R., Sh, S., \& Zain, A. (2016). The Relationship of Physical Activity and Human Comfort in Urban Park. Asian Journal of Behavioral Studies, 2(july/August), 36-48.

Aye, M., Cabot, J. S. F., \& Sazali, M. (2015). Study of Coronary Risk Factors in Rural Malaysia Population. International Journal of Medical Biology, 2, 1-7. https://doi.org/10.4303/ijmb/235922

Dahlan, A., Anwar, S., \& Ibrahim, S. (2017). An Activity Program for Older People. Asian Journal of Quality of Life, AjQoL, 2(6), 1-10.

Ellis, T., Latham, N. K., DeAngelis, T. R., Thomas, C. a, Saint-Hilaire, M., \& Bickmore, T. W. (2013). Feasibility of a virtual exercise coach to promote walking in community-dwelling persons with Parkinson disease. American Journal of Physical Medicine \& Rehabilitation / Association of Academic Physiatrists, 92, 472-81-5. https://doi.org/10.1097/PHM.0b013e31828cd466

Fairhall, N., Sherrington, C., Kurrle, S. E., Lord, S. R., Lockwood, K., \& Cameron, I. D. (2012). Effect of a multifactorial interdisciplinary intervention on mobility-related disability in frail older people: randomised controlled trial. BMC Medicine, 10(1), 120. https://doi.org/10.1186/1741-7015-10-120

Fujimoto, N., Prasad, A., Hastings, J. L., Arbab-Zadeh, A., Bhella, P. S., Shibata, S., ... Levine, B. D. (2010). Cardiovascular effects of 1 year of progressive and vigorous exercise training in previously sedentary individuals older than 65 years of age. Circulation, $122(18)$, $1797-805$. https://doi.org/10.1161/CIRCULATIONAHA.110.973784

Hussein, H., Nik Zainal Abidin, N. M., \& Omar, Z. (2016). Sensory Gardens: A multidisciplinary effort. Asian Journal of Behavioural Studies, 1(1), 49-63. https://doi.org/10.21834/ajbes.v1i1.18

Hussein, H., Omar, Z., \& Ishak, S. A. (2016). Sensory Garden for an Inclusive Society. Asian Journal of Behavioural Studies, 1(4), 33. https://doi.org/10.21834/ajbes.v1i4.42

Ismail, F., Ahmad, N., Afida, N., Janipha, I., \& Ismail, R. (2017). The Behavioural Factors ' Characteristics of Safety Culture. Journal of ASIAN Behavioural Studies, 2(4), 91-98

Karim, H., \& Rashid, S. (2010). Community Participation: Towards a Safer Housing Environment. Asian Journal of Environment-Behaviour ..., 2(2), 19-32. https://doi.org/10.21834/aje-bs.v2i2.176

Laurens, J. M. (2012). Intervention program to change the pro-environmental behavior of the Riverside community. Journal of Asian Behavioural Studies, 2(3), 45-56. https://doi.org/10.21834/jabs.v2i3.193 
Magistro, D., Liubicich, M. E., Candela, F., \& Ciairano, S. (2013). Effect of Ecological Walking Training in Sedentary Elderly People: Act on Aging Study. The Gerontologist. https://doi.org/10.1093/geront/gnt039

Majid, H. A. M. A., Danis, A., Sharoni, S. K. A., \& Khalid, M. (2015). "Whole School Environmental Mapping Framework and Observation" in Preventing Childhood Obesity. Procedia - Social and Behavioral Sciences, 201(February), 102-109. https://doi.org/10.1016/j.sbspro.2015.08.137

Mamat, M. N., Mahamood, S. F., \& Ismail, I. (2012). Islamic Philosophy on Behaviour - Based Environmental Attitude. Procedia - Social and Behavioral Sciences, 49(2), 85-92. https://doi.org/10.1016/j.sbspro.2012.07.008

Mansor, M., Said, I., \& Mohamad, I. (2012). Experiential Contacts with Green Infrastructure's Diversity and Well-being of Urban Community. Procedia - Social and Behavioral Sciences, 49(2), 257-267. https://doi.org/10.1016/j.sbspro.2012.07.024

Mcphee, J. S., French, D. P., Jackson, D., Nazroo, J., Pendleton, N., \& Degens, H. (2016). Physical activity in older age : perspectives for healthy ageing and frailty Biogerontology, 17(3), 567-580. https://doi.org/10.1007/s10522-016-9641-0

Md Jani, H. H., Harun, N. Z., Mansor, M., \& Zen, I. (2017). Discovering the Values of the Islamic Garden. Asian Journal of Behavioural Studies, 2(5), 11 https://doi.org/10.21834/ajbes.v2i5.45

Nirfalini, D., \& Majid, A. (2016). The Criteria of Residential Satisfaction in Gated Community : Medan City. Asian Journal of Behavioural Studies, 1(3), 41-50.

Omar, D., Illia, F., Hanita, N., \& Mohamad, N. (2017). Open Spaces and Human Interaction. Asian Journal of Behavioural Studies, 37-46.

Samsuddin, N. M., Takim, R., \& Nawawi, A. H. (2017). Human Behaviour and Resilience Hospital. Asian Journal of Behavioural Studies, $2(5), 21$. https://doi.org/10.21834/ajbes.v2i5.46

Shepherd, S. O., Cocks, M., Tipton, K. D., Witard, O. C., Ranasinghe, A. M., Barker, T. A., ... Shaw, C. S. (2014). Resistance training increases skeletal muscle oxidative capacity and net intramuscular triglyceride breakdown in type I and II fibres of sedentary males. Exp Physiol, 996, 894-908. https://doi.org/10.1113/expphysiol.2014.078014

Shukur, F., Othman, N., \& Nawawi, A. H. (2012). The Values of Parks to the House Residents. Procedia - Social and Behavioral Sciences, 49(6), 350-359. https://doi.org/10.1016/j.sbspro.2012.07.033

Yousefi, Z., Hosseini, S., Yazdanfar, S., \& Norouzian-maleki, S. (2017). Promoting the Residents ' Sense of Belonging in Housing Design. Asian Journal of Behavioural Studies, 2(5), 33. https://doi.org/10.21834/ajbes.v2i5.47 